\title{
Differential Capacitance of Electric Double Layer - Influence of Asymmetric Size of Ions, Thickness of Stern Layer and Orientational Ordering of Water Dipoles
}

\author{
Aleš Iglič, ${ }^{1,2,{ }^{*}}$ Ekaterina Gongadze ${ }^{1}$ and Veronika Kralj-Iglič ${ }^{3}$ \\ ${ }^{1}$ Laboratory of Physics, Faculty of Electrical Engineering, University of Ljubljana, \\ Tržaška cesta 25, SI-1000 Ljubljana, Slovenia \\ ${ }^{2}$ Laboratory of Clinical Biophysics, Faculty of Medicine, University of Ljubljana, \\ Zaloška 9, SI-1000 Ljubljana, Slovenia \\ ${ }^{3}$ Laboratory of Clinical Biophysics, Faculty of Health Sciences, University of Ljubljana, \\ Zdravstvena pot 5, SI-1000 Ljubljana, Slovenia \\ *Corresponding author: E-mail: ales.iglic@fe.uni-lj.si
}

Received: 08-02-2019

\begin{abstract}
The mean-field theoretical model of the electric double layer which takes into account the asymmetric finite size of anions and cations and the orientational ordering of water dipoles in the Stern and the diffuse layers is described together with a short description of the main concepts and a brief review of the literature in the theory of the electric double layer. As an example of the application of the described mean-field lattice model of the electric double layer, the influence of different sizes of anions and cations, the influence of the thickness of the Stern layer and the influence of the orientational ordering of water molecules on the asymmetric, bimodal camel-like dependence of differential capacitance on the surface potential is theoretically considered.

The presented theoretical model of the electric double layer is flexible enough to be in the future extended to more complicated multicomponent systems with molecules of different sizes and the orientational ordering of molecules.
\end{abstract}

Keywords: Asymmetric size of ions; relative permittivity; water ordering; Stern layer; differential capacitance

\section{Introduction}

Strong interactions between the charged surface and ions in electrolyte solution result in the formation of the electric double layer (EDL) in the close vicinity of the charged surface. ${ }^{1}$ In EDL, the ions with the electric charge of the opposite sign than the charged surface (counterions) are accumulated, while the ions with a charge of the same sign as the surface (coions) are depleted from the space close to the charged surface (Fig. 1). Due to a high magnitude of electric field strength in EDL, the water dipoles near the charged surface are strongly oriented ${ }^{2,3}$ (Fig. 1). Due to a non-homogeneous distribution of ions and water molecules and the orientation of water molecules in EDL, the electric field strength is screened at larger distances from the charged surface. ${ }^{1}$
EDL has been theoretically first described by Helmholtz ${ }^{4}$ who neglected the effects of entropy and proposed that a single layer of counterions is formed at the charged surface. Later, Gouy and Chapman described the spatial distribution of point-like coions and counterions by Boltzmann distributions ${ }^{5,6}$ corresponding to the minimum of the system free energy. ${ }^{7}$ The finite size of coions and counterions has been first described by Stern ${ }^{8}$ by introducing the distance of the closest approach (Fig. 1) and has later been developed further by Bikerman, Eigen, Wicke, Freise $^{9-12}$ and many other authors. ${ }^{13-24,25-28}$

The orientational ordering of the water dipoles in the electric field near the charged surface (Fig. 1) has been shown to strongly influence the electric field in the Stern and the diffuse layers, among others reflected also in a strong local decrease in relative permittivity. ${ }^{30-43}$ The de- 


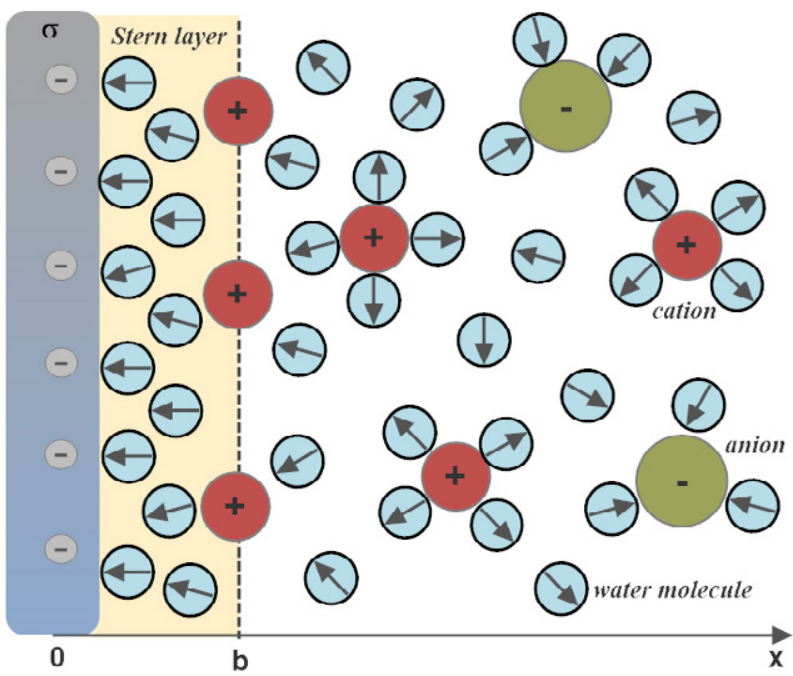

Figure 1. A schematic figure of electrolyte solution near a negatively charged planar surface $(\sigma<0)$, consisting of the Stern layer $(0 \leq x$ $\leq b)$ and the diffuse layer $(b \leq x \leq \infty)$, where $b$ denotes the thickness of the Stern layer, approximately equal to the distance of the closest approach of hydrated counterions. Sodium cations are weakly hydrated and have a tendency to disrupt the aqueous bulk structure without strongly ordering the water molecules. ${ }^{29}$ Chemisorbed or adsorbed ions are taken into account in the value of the surface charge density $\sigma$.

crease in the relative permittivity near the charged surface is influenced also by the excluded volume effect due to the competition between counterions and water molecules. ${ }^{2,35}$

Based on the ideas of some previous studies, $, 12,44,45$ the mean-field model of EDL which takes into account the asymmetry of the anion and cation finite sizes and the orientational ordering of water molecules was introduced recently. ${ }^{46}$ This model, named here as the modified Gongadze-Iglič (GI) model, ${ }^{2,46,47}$ is shortly described in the following section.

\section{Modified GI Model}

The water molecules in the modified GI lattice mod$\mathrm{el}^{2,46}$ were described within the modified Kirkwood approach $^{45}$ as point-like dipoles at the centers of finite sized spheres with permittivity equal to the square of the optical refractive index of water $n .{ }^{34}$

Within the modified GI model, the expressions for the spatial dependencies of the number densities of monovalent cations $\left(n_{+}(x)\right)$, anions $\left(n_{-}(x)\right)$ and water $\left(n_{\mathrm{w}}(x)\right)$ in the electrolyte solution can be derived by using the method of lattice statistics with Boltzmann correction factors. ${ }^{2,46}$ The method of lattice statistics with Boltzmann correction factors has been shown to be equivalent to the method of minimization of the free energy of the system. ${ }^{40,48}$ The number of densities $\left(n_{+}(x),\left(n_{-}(x)\right.\right.$ and $\left(n_{\mathrm{w}}(x)\right.$ are thus proportional to the probabilities that a single lat-

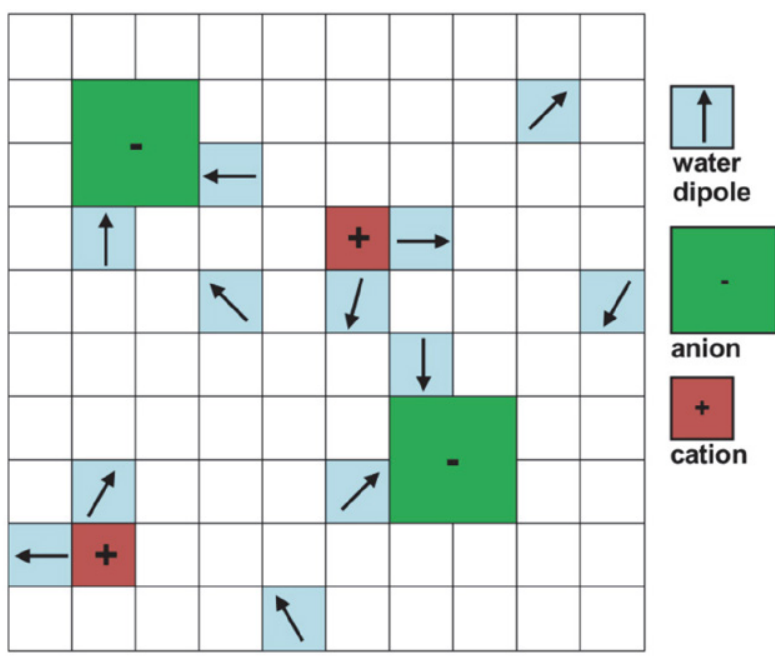

Figure 2. Lattice model of electrolyte solution. ${ }^{46}$ The single positive ion and the single negative ion, each of them together with the surrounding water molecules, occupy $\alpha_{+}$and $\alpha_{-}$lattice sites, respectively. In the schematic figure $\alpha_{+}=3$ and $\alpha_{-}=6$, while a single water molecule occupies just one lattice site. In the model, it is assumed that the water molecules and the ions in the hydration layer which contribute to $\alpha_{+}$and $\alpha_{-}$give rise to electronic polarization only, described by the term $n^{2}$ in Eq. (6). It is therefore assumed that the water dipoles which composed the hydration layer around positive or negative ions do not contribute to the orientational ordering/polarization in the electrolyte solution.

tice site in the bulk solution is occupied by one of the three particles (i.e., cations, anions or water molecules): ${ }^{2,46}$

$$
\begin{aligned}
n_{+}(x)= & n_{0} e^{-e_{0} \phi \beta} \frac{n_{s}}{\mathcal{D}_{A}(\phi, E)} \\
n_{-}(x)= & n_{0} e^{e_{0} \phi \beta} \frac{n_{s}}{\mathcal{D}_{A}(\phi, E)} \\
n_{w}(x)= & \frac{n_{0 w} n_{s}}{\mathcal{D}_{A}(\phi, E)} \frac{\sinh \left(\gamma p_{0} E \beta\right)}{\gamma p_{0} E \beta} \\
\mathcal{D}_{A}(\Phi)= & \alpha_{+} n_{0} e^{-e_{0} \phi \beta}+\alpha_{-} n_{0} e^{+e_{0} \phi \beta}+ \\
& +\frac{n_{0 w}}{\gamma p_{0} E \beta} \sinh \left(\gamma p_{0} E \beta\right),
\end{aligned}
$$

where it is assumed that all lattice sites are occupied, i.e. $n_{s}$ $=\alpha_{+} n_{+}(x)+\alpha_{-} n_{-}(x)+n_{\mathrm{w}}(x)$.

Here, the parameters $\alpha_{+}$and $\alpha_{-}$are the number of lattice sites occupied by a single positive and negative hydrated ion, respectively ${ }^{46}$ (Fig. 2). A single water molecule occupies just one lattice site, therefore the reduced number density of lattice sites $n_{s} / N_{A}=55 \mathrm{~mol} / \mathrm{l}$ is equal to the concentration of pure water. The symbol $n_{0 w}$ stands for the bulk number density of water molecules, $n_{0}$ is the bulk number density of anions and cations, $\beta=1 / k T, k T$ is thermal energy, $e_{0}$ is unit charge, $\phi$ is electric potential, $p_{0}$ is magnitude of the external water dipole moment, ${ }^{46,48} E$ is magnitude of electric field strength, $x$ is distance from the 
negatively charged planar surface (Fig. 1), $\gamma$ is given by ${ }^{34,46}$ : $y=\left(2+n^{2}\right) / 2$ and $n$ is optical refractive index of water. In bulk, $n_{s}=\alpha_{+} n_{0}+\alpha_{-} n_{0}+n_{0 \mathrm{w}}$.

In the model, a single ion together with water molecules in its first hydration layer do not contribute to orientational polarization in the solution because the orientations of the water dipoles around the ions are predominantly determined by the ion. ${ }^{2}$ This assumption is in accordance with the model of Giese et al., ${ }^{49}$ where the authors proposed that each ion together with the strongly interacting surrounding water molecules does not contribute to the orientational polarization in the electrolyte solution and is considered to be a sphere consisting of a homogeneous dielectric medium with permittivity equal to 2 . In our model, ${ }^{46}$ it is assumed that the relative permittivity of water due to electronic polarizability is equal to the square of refractive index $\left(n^{2} \cong 1.8\right.$, where $\left.n=1,33\right)$ (see Eqs. (7) and (8)), which is the value very close to 2 .

The Poisson's equation for the region $x \geq b$ (see Fig. 1) can be written as: ${ }^{30,46}$

$$
\frac{d}{d x}\left[\varepsilon_{0} \varepsilon_{r}(x) \frac{d \phi}{d x}\right]=2 e_{0} n_{s} n_{0} \frac{\sinh \left(e_{0} \phi \beta\right)}{\mathcal{D}_{A}(\phi, E)},
$$

where $\varepsilon_{r}(x)$ is the spatial dependence of the relative permittivity:

$$
\varepsilon_{r}(x)=n^{2}+n_{0 w} n_{s} \frac{p_{0}}{\varepsilon_{0}}\left(\frac{2+n^{2}}{3}\right)\left(\frac{\mathcal{F}\left(\gamma p_{0} E \beta\right)}{\mathcal{D}_{A}(\phi, E) E}\right)
$$

and $\varepsilon_{0}$ is the permittivity of free space. The function $\mathcal{F}(u)$ is defined as $\mathcal{F}(u)=\mathcal{L}(u)(\sinh u / u)$, where $\mathcal{L}(u)$ is the Langevin function. Eq. (6) predicts the linear decreasing of the relative permittivity in the bulk solution with an increasing salt concentration and gives the value of $\varepsilon_{r, b} \cong 78.5$ for zero bulk salt concentration. ${ }^{46,2}$

The described modified GI model includes the Helmholtz/Stern layer filled with water dipoles ${ }^{30,50,51}$ (see Fig. 1). The thickness of the Helmholtz/Stern layer is defined by the distance of closest approach (Fig. 1), which is not the same for cations and anions (see for example $\mathrm{e}^{50-54}$ ). In the Stern layer (Fig. 1), there are no free ions close to the charged surface, i.e., $n_{+}(x)=n_{-}(x)=0$. Therefore, in the Stern layer, the general expression for the relative permittivity $\varepsilon_{r}(x)$ (Eq. (6)) transforms into: ${ }^{50,51}$

$$
\varepsilon_{s}=n^{2}+n_{s} \frac{p_{0}}{\varepsilon_{0}}\left(\frac{2+n^{2}}{3}\right) \frac{\mathcal{L}\left(\gamma p_{0} E \beta\right)}{E} .
$$

Note that the ions which are adsorbed and/or chemisorbed to the charged surface are taken into account in the model by the appropriately modified value of the surface charge density at $\mathrm{x}=0$ (Fig. 1). Combining the boundary condition $d \phi / d x(\mathrm{x}=0)=-\sigma / \varepsilon_{0} \varepsilon_{s}$ (see Fig. 1) and Eq. (7) results in the non-linear equation for the magnitude of electric field, $E$, in the Stern layer: ${ }^{30,50,51}$

$$
\varepsilon_{0} E\left(n^{2}+n_{s} \frac{p_{0}}{\varepsilon_{0}}\left(\frac{2+n^{2}}{3}\right) \frac{\mathcal{L}\left(\gamma p_{0} E \beta\right)}{E}\right)=|\sigma| .
$$

Inserting the calculated value of $E$ in Eq. (7) gives the value of the relative permittivity in the Stern layer $\left(\varepsilon_{s}\right)$ for a given surface charge density $\sigma$. In this way, it was shown that relative permittivity in the Stern layer $\left(\varepsilon_{s}\right)$ strongly decreases with the increasing magnitude of $\sigma$ due to the saturation of the orientational ordering of water dipoles in a strong electric field at large values of $\sigma^{2,34,50}$ (see also Fig. 4).

In the next section of the present paper, we examine the influence of asymmetric size of ions, the thickness of the Stern layer and the orientation of water dipoles in the Stern and the diffuse layers on the differential capacitance of the electric double layer calculated within the modified GI model.

\section{Results and Discussion}

Fig. 3 shows the calculated dependence of electric potential in the Stern and the diffuse double layers at the distance from the charged plane (Fig. 1). It can be that within the Stern layer, depleted of charged particles, the electric potential depends linearly on the distance from the charged surface at $x=0$ (see also Fig. 1). Accordingly, the electric field strength in this region with zero volume charge distribution is constant and can be determined from Eq. (8). As a consequence, the relative permittivity is also constant in the Stern layer in the whole layer. However, as shown in Fig. 4, relative permittivity in the Stern layer $\left(\varepsilon_{s}\right)$ (Fig. 4B) and electric field strength (Fig. 4A) strongly depend on the surface charge density $\sigma$. Therefore, the

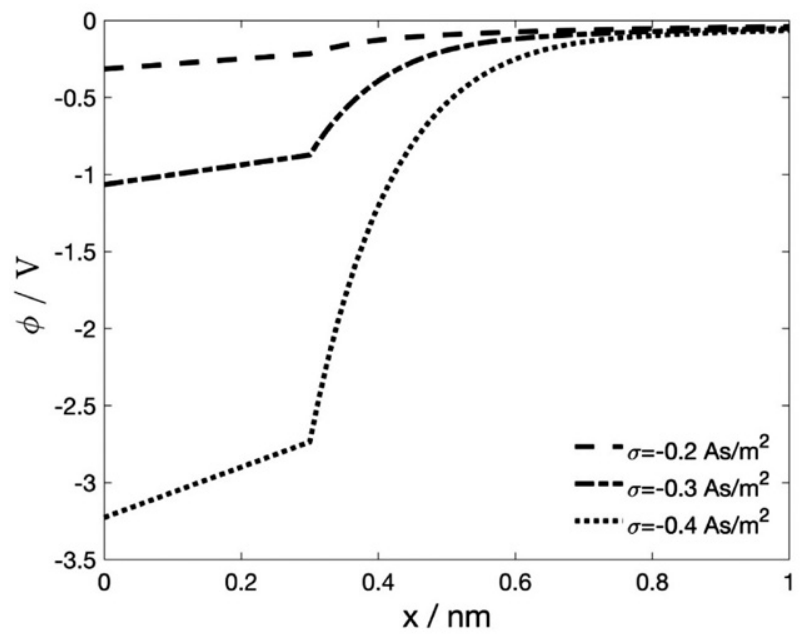

Figure 3. Electric potential as a function of the distance from the charged surface for different values of surface charge density $\sigma$, calculated within the modified GI model for and $\alpha_{+}=5$ and $\alpha_{-}=2$ (for definition of $\alpha_{+}$and $\alpha_{-}$see Fig. 2), the thickness of the Stern layer $b$ $=0.3 \mathrm{~nm}$ (see Fig. 1 for definition) and the bulk concentration of ions $n_{0} / N_{A}=0,15 \mathrm{~mol} / \mathrm{l}$. The values of other model parameters are: $n=1.33, p_{0}=3.1 \mathrm{D}^{46}, n_{\mathrm{s}} / N_{A}=55 \mathrm{~mol} / \mathrm{l}^{2,30}$ and $T=298 \mathrm{~K}$. 
assumption of constant relative permittivity in the Stern layer, as assumed in many theoretical models of the electric double layer (see for example ${ }^{55}$ and references therein), is not realistic.

The strong dependence of relative permittivity in the Stern layer (Fig. 4B) is a consequence of the orientational ordering of water dipoles in this layer (Fig. 4C), which can certainly not be neglected as suggested in some oversimplified macroscopic phenomenological theoretical models ${ }^{55}$, based on the $19^{\text {th }}$ century Maxwell's mixture formula. ${ }^{56}$

The predicted decrease in relative permittivity in the Stern and the diffuse layers is clearly to a large extent a consequence of the orientational ordering of water dipoles close to the saturation regime (Fig. 4C) as proved theoretically in ${ }^{31,34,37,40,46,57,58}$ and on the other hand totally neglected in phenomenological approaches. ${ }^{55}$ Neglecting the statistical mechanics approach and the orientational ordering of water molecules in electrolyte solution close to the charged surface cannot contribute to a better understanding of the physics of the electric double layer.

It was further proposed recently by Lopez-Garcia et al. ${ }^{55}$ that close to the charged surface nearly all water molecules belong to water shells around the ions, while free water molecules practically do not exist in this region. The results of Monte Carlo (MC) simulations ${ }^{59}$ strongly oppose this assumption ${ }^{55}$ and clearly show the increased ordering of water dipoles in the direction towards the charged surface (including Stern region) ${ }^{59}$ as predicted also within the GI model (see Fig. 4C). MS simulations predict strong orientational ordering in the vicinity of the charged surface even for high salt concentrations, also in agreement with our theoretical predictions (Fig. 4C). Strikingly, MC simulations show practically no difference in the average orientation and space distribution of water dipoles close to the charged surface in the case without $\mathrm{NaCl}$ and with $\mathrm{NaCl}$ (at concentration $0.5 \mathrm{~mol} / \mathrm{l} \mathrm{NaCl}$ ) in water solution. ${ }^{59}$ In general, for low enough magnitudes of the surface charge density, where the mean-field approach is valid, the profile of the average orientation of water dipoles in the Stern and the diffuse layers is only weakly influenced by salt concentration..$^{59}$

It is argued in ${ }^{55}$ that in the modified GI model, ${ }^{46}$ described also in this paper, the space occupied by the ions behaves just as a vacuum. This is certainly not true since the modified GI model ${ }^{46}$ assumes that the permittivity of hydrated ions is equal to the square of the refractive index of water (see also ${ }^{2,3,28,45,46,48}$ ). This means that in the modified GI model, the electronic polarizability of hydrated ions is equal to the electronic polarizability of water. $^{30,34,46,48}$ In addition, the authors of ${ }^{55}$ also completely overlooked that the modified GI model ${ }^{46}$ is not based on the limiting Onsager model, but instead on the generalized Kirkwood-Onsager-Fröhlich's theory ${ }^{2,3,45}$ which is valid also in the saturation regime of the water dipole orientation and polarization.
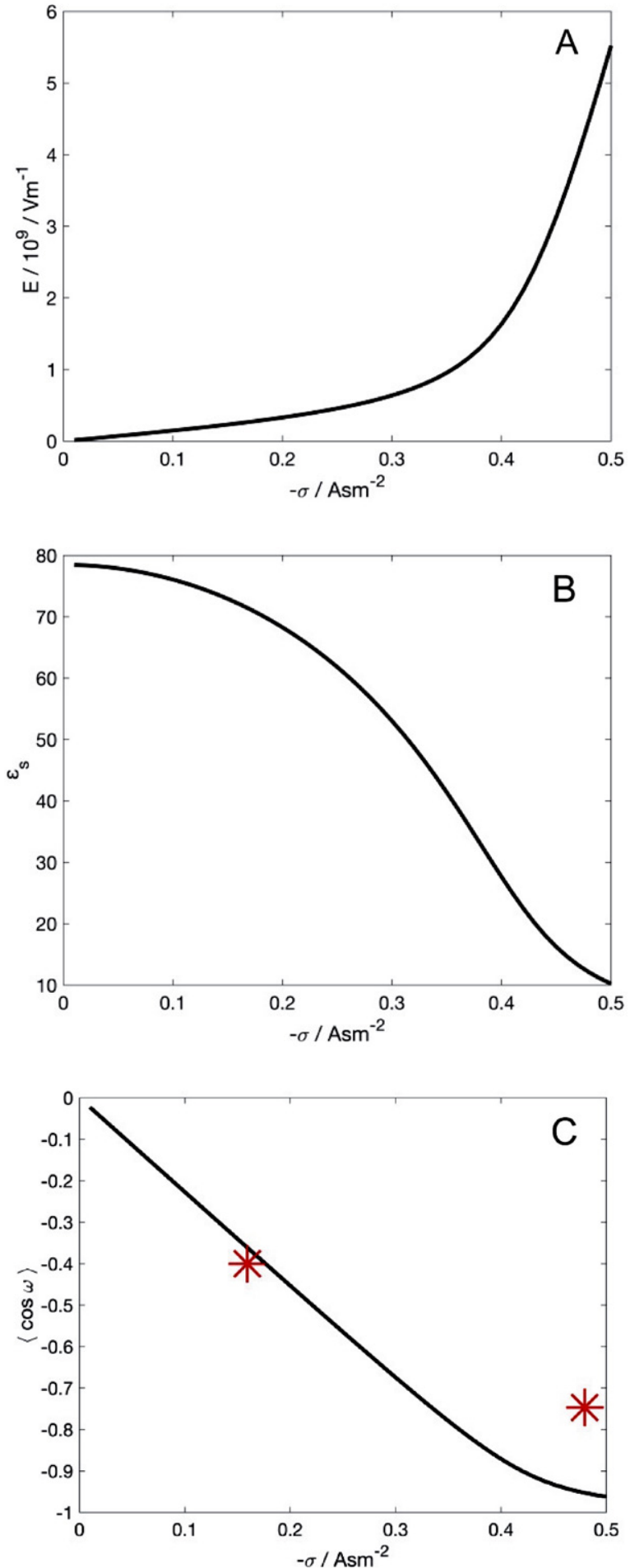

Figure 4. The magnitude of the electric field strength $E$ (panel A), relative permittivity (panel B) and the average orientation of water dipoles (panel C) in the Stern layer calculated as a function of the surface charge density $\sigma$. The average orientation of water molecules is described by the average $\cos (\omega)$ (panel C), where $\omega$ is the angle between the gradient of the electric potential and the vector of the water dipole moment. ${ }^{35,48}$ The two asterisks denote the values of the average $\cos (\omega)$ determined by Monte-Carlo simulations. ${ }^{59}$ The values of the model parameters are: $p_{0}=3.1 \mathrm{D}, \alpha_{+}=5$ and $\alpha_{-}=2, b=0$, the bulk concentration of ions, $n_{0} / N_{A}=0.5 \mathrm{~mol} / \mathrm{l}, n=1.33, n_{s} / N_{A}=$ $55 \mathrm{~mol} / \mathrm{l}$ and $T=298 \mathrm{~K}$. 

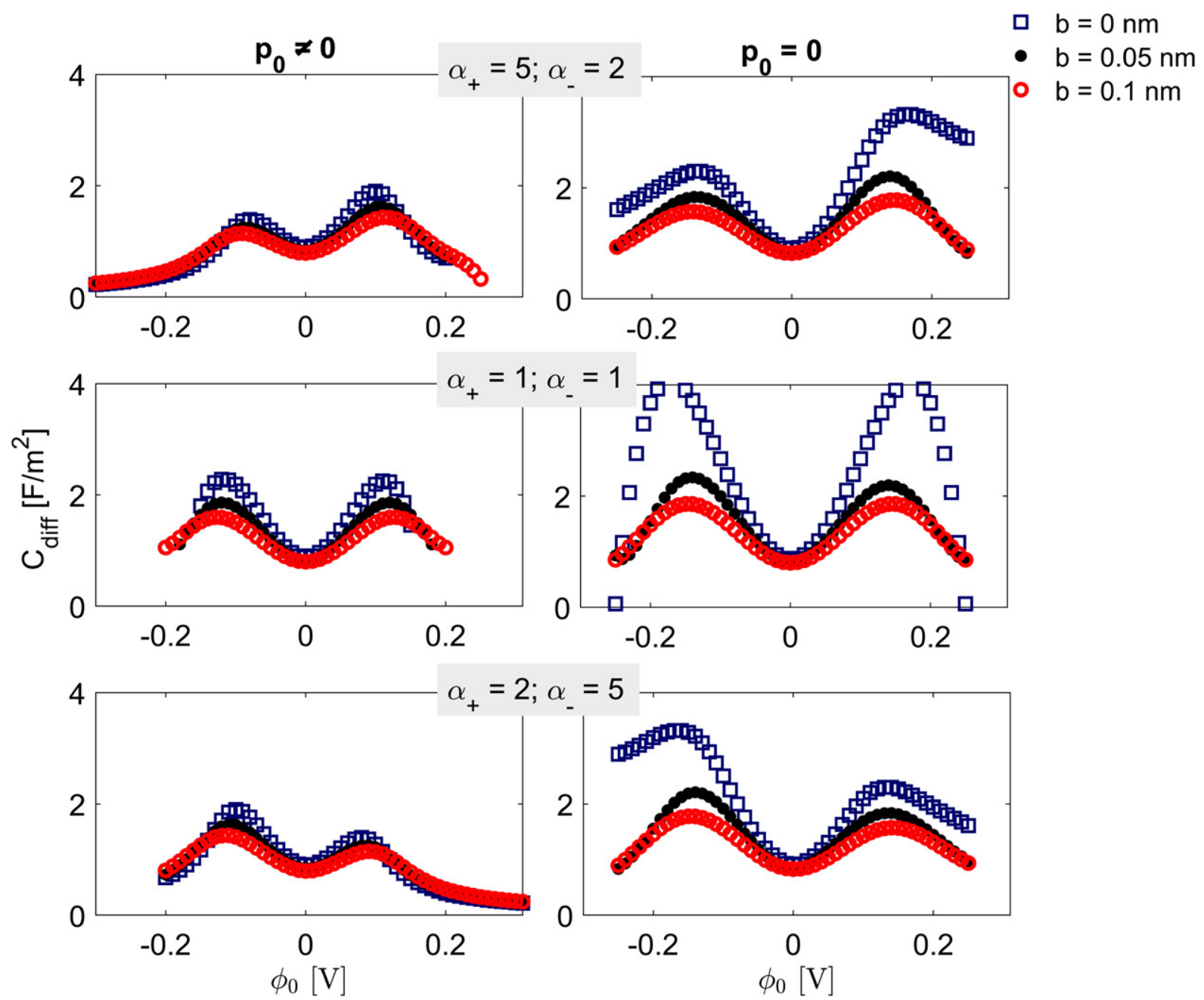

Figure 5. Calculated differential capacitance as a function of the surface potential $\phi_{0}$ for different combinations of the values of parameters $\alpha_{+}$and $\alpha_{-}$and different values of the thickness of the Stern layer $b$ calculated for $p_{0}=3.1 \mathrm{D}$ (left panels) and $p_{0}=0$ (right panels) within the modified GI model. The values of the other model parameters are: bulk concentration of ions $n_{0} / N_{A}=0.15 \mathrm{~mol} / \mathrm{l} . n=1.33, n_{0} / N_{A}=55 \mathrm{~mol} / \mathrm{land} \mathrm{T}=298 \mathrm{~K}$.

Fig. 5 shows differential capacitance $C_{\text {diff }}=d \sigma / d \phi_{0}$ as a function of surface potential $\phi_{0}=\phi(x=0)$ calculated within the modified GI model for different values of parameters $\alpha_{+}$and $\alpha_{-}$, different values of the thickness of the Stern layer $(b)$ and two values of the magnitude of the external water dipole moment $\left(p_{0}\right)$. It can be seen in Fig. 5 that the consideration of non-zero $p_{0}$ and the orientation ordering of water dipoles in the electric double layer decreases the calculated differential capacitance of EDL.

In general, the differential capacitance first increases with increasing absolute value the surface potential $\phi_{0}$ and after first reaching its maximum, it starts to strongly decrease, attaining the so-called bimodal camel-like dependence of differential capacitance on $\phi_{0}$, similarly as observed in experiments, ${ }^{60,61}$ in Monte-Carlo ${ }^{62}$ and also in molecular dynamic simulations. ${ }^{63}$

Neglecting the finite size of ions (the Gouy-Chapman approach) would lead to monotonously increasing the differential capacitance with the increasing absolute value of $\phi_{0} .{ }^{64}$ As shown in Fig. 5, asymmetry in the finite size of positive and negative ions (i.e. $\alpha_{+} \neq \alpha_{-}$) leads to asymmetric bimodal camel-like dependence of differential capacitance on the surface potential as observed also in experiments. ${ }^{60,61,65}$

It can be further seen in Fig. 5 that the increased thickness of the Stern layer (b) (see Fig. 1) decreases the differential capacitance. The increased thickness of the Stern layer $(b)$ also moves the surface potential to higher absolute values. ${ }^{30,50}$ Considering different values of the thickness of the Stern layer for positive and negative $\phi_{0}$, i.e. different distance of closest approach for hydrated negative and positive counterions, ${ }^{51}$ would additionally change the relative height of both maxima of the differential capacitance asymmetric camel-like curve. ${ }^{51}$ Namely, in the case of negatively charged surface, the distance of closest approach $b$ is defined by positively charged counterions, while in the case of positively charged surface, the parameter $b$ describes the distance of closest approach for 
negatively charged counterions. ${ }^{51}$ It was thus shown ${ }^{51}$ that the differential capacitance curve becomes asymmetric also when only different values of the thickness of the Stern layer $(b)$ are used for negative and positive surface potential $\phi_{0}$ and the potential (charge) dependent relative permittivity in the Stern layer is taken into account, ${ }^{2,28,34}$ while the finite asymmetric size of ions in the diffuse layer is neglected.

To conclude, different values of the thickness of the Stern layer $(b)$ for negative and positive surface potential $\phi_{0}$ mean that the distance of closest approach is not the same for negatively and positively charged counterions. In Fig. 5, we should therefore take into account that the thickness of the Stern layer $(b)$ is not the same for negative and positive values of the surface potential $\phi_{0}$, i.e. in Fig. 5 , the value of $b$ for positive $\phi_{0}$ is not the same as the value of $b$ for negative $\phi_{0}$.

\section{Conclusions}

In this paper we describe the modified GI mod$\mathrm{el}^{2,46,47,66}$ of the electric double layer, which takes into account within the mean-field theoretical approach the finite and asymmetric size of anions and cations and the orientational ordering of water dipoles in the Stern and the diffuse layers. The modified GI model ${ }^{46}$ can be derived either by the minimization of the free energy of the system ${ }^{7,40,48,66}$ or by applying the method of lattice statistics with Boltzmann correction factors ${ }^{46,66,67}$ which has been shown to be equivalent to the method of the minimization of the free energy of the system. ${ }^{48,66,67}$ The model predicts a decrease in the relative permittivity in electrolyte solution near the charged surface, including a decrease in the relative permittivity in the Stern layer (Fig. 4B). The decrease in the relative permittivity is a consequence of saturation in an average orientational ordering of water dipoles (Fig. 4C) at high electric field strengths (Fig. 4A). In accordance with experimental observation, an asymmetric bimodal camel-like dependence of differential capacitance on the surface potential was predicted, where the relative height of both maxima of the curve depends on the asymmetric size of the anions and cations, the orientational ordering of water dipoles in the Stern and the diffuse layers and the values of the thickness of the Stern layer $(b)$ for negative and positive surface potential $\phi_{0}$.

To conclude, it was recently pointed out by Zhang and Huang ${ }^{47}$ that the modified GI model ${ }^{46}$ captures all the major phenomena of the asymmetric ion-size effect and is also flexible enough to be extended in the future to more complicated multicomponent systems as it is just a simple binary electrolyte water solution. In comparison to the most of the other mean-field EDL models, the GI mod$\mathrm{el}^{46,2,30}$ contains also the statistical mechanical description of the water dipole orientational ordering in EDL, a phenomenon which is not included in the other theoretical mean-field models of asymmetric ion-size effect in $\mathrm{EDL}^{47}$, but is essential to realistically describe the physical properties of EDL, as indicated also in this paper.

\section{Acknowledgements}

\section{Funding}

This work was partly supported by the Slovenian Research Agency (ARRS), grants numbers P2-0232, P3-0388, J5-7098, J3-9262, J1-9162, J2-8166 and J2-8169.

\section{Author biographies}

Prof. ddr. Aleš Iglič received his B.Sc. and Ph.D. degrees in physics, M.Sc. degree in biophysics and his second Ph.D. degree in electrical engineering, all from the University of Ljubljana, in 1994 and 1995, respectively. He is currently a professor and head of the Laboratory of Physics at the Faculty of Electrical Engineering at the University of Ljubljana. His research interests are in physics of electric double layer, electrostatics and statistical physics of biological membranes, synthesis of inorganic nanomaterials and interactions of inorganic nanomaterials with biological cells and liposomes. Since 2009, he has been the editor of the Elsevier book series Advances in Biomembranes and Lipid Self-Assembly. He is the coordinator of the interdisciplinary doctoral study Nanosciences at the University of Ljubljana. He has been a supervisor or co-supervisor to more than $25 \mathrm{Ph} . \mathrm{D}$. and postdoctoral students.

Dr. Ekaterina Gongadze received her B.Sc. degree from the Faculty of Industrial Engineering at the Technical University of Sofia in 2006 and her M.Sc. and Dr. Ing. degree from the Faculty of Computer Science and Electrical Engineering at the University of Rostock in 2008 and 2012, respectively. She is currently working as a senior research associate at the Faculty of Engineering at the University of Bristol, United Kingdom, and as a research associate in Laboratory of Physics, Faculty of Electrical Engineering at the University of Ljubljana. Her research interests are in numerical modeling and simulation.

Prof. dr. Veronika Kralj-Iglič received her B.Sc. and Ph.D. degrees in physics and M.Sc. degree in biophysics from the Department of Physics at the University of Ljubljana. She is a professor of biophysics at the same university. Her research interests are in biophysics and medicine of extracellular vesicles, electrostatics, biomechanics and statistical physics of biological membranes and biomechanics of the hip. She is head of the Laboratory of Clinical Biophysics at the Faculty of Health Sciences of the University of Ljubljana. She is the coordinator of the interdisciplinary doctoral study Bioengineering in Health Sciences at the University of Ljubljana. She has been a supervisor or co-supervisor to 22 Ph.D. doctoral students. 


\section{References}

1. S. McLaughlin, Ann. Rev. Biophys. Chem. 1989, 18, 113-136. DOI:10.1146/annurev.bb.18.060189.000553

2. E. Gongadze, L. Mesarec, V. Kralj-Iglič, A. Iglič, Mini-Rev. Med. Chem. 2018, 18, 1559-1566.

DOI:10.2174/1389557518666180626111927

3. F. Booth, J. Chem. Phys. 1951, 19, 391-394. DOI:10.1063/1.1748233

4. H. Helmholtz, Ann. Phys. 1879, 243, 337-382. DOI:10.1002/andp.18792430702

5. M. G. Gouy, J. Phys. Radium 1910, 9, 457-468. DOI:10.1051/jphystap:019100090045700

6. D. L. Chapman, Philos. Mag. 1913, 6, 475-481. DOI:10.1080/14786440408634187

7. V. Kralj-Iglič, A. Iglič, J. Phys. II (France) 1996, 6, 477-491.

8. O. Stern, Z. Elektrochemie 1924, 30, 508-516.

9. J. J.Bikerman, Phil. Mag. 1942, 33, 384-397. DOI:10.1080/14786444208520813

10. E. Wicke, M. Eigen, Z. Elektrochem. 1952, 38, 551-561.

11. V. Freise, Z. Elektrochem. 1952, 56, 822-827.

12. M. Eigen, E. Wicke, J. Phys. Chem. 1954, 58, 702-714. DOI:10.1021/j150519a007

13. S. Lamperski, C. W. Outhwaite, Langmuir 2002, 18, 34233424. DOI:10.1021/la011852v

14. L. Bhuiyan, C. Outhwaite, J. Coll. Int. Sci. 2009, 331, 543-547 DOI:10.1016/j.jcis.2008.11.059.

15. S. Kenkel, J. MacDdonald, J. Chem. Phys. 1984, 81, 3215-3222. DOI:10.1063/1.448028

16. P. Nielaba, F. Forstmann, Chem. Phys. Lett. 1985, 117, 46-48. DOI:10.1016/0009-2614(85)80402-4

17. C. Caccamo, G. Pizzimenti, L. Blum, J. Chem. Phys. 1986, 84, 3327-3335. DOI:10.1063/1.450267

18. R. Kjellander, S. Marčelja, Chem. Phys. Lett. 1986, 127, 402407. DOI:10.1016/0009-2614(86)80304-9

19. M. Plischke, D. Henderson, J. Chem. Phys. 1988, 88, 27122718. DOI:10.1063/1.454001

20. L. Mier-y-Teran, S. Suh, H. White, H. Davis, J. Chem. Phys. 1990, 92, 5087-5098. DOI:10.1063/1.458542

21. P. Strating, F. Wiegel, J. Phys. A Math. Gen. 1993, 26, 33833391. DOI:10.1088/0305-4470/26/14/007

22. I. Borukhov, J. Polym. Sci. Part B: Polym. Phys. 2004, 42, 3598-3615. DOI:10.1002/polb.20204

23. G. Torrie, J. Valleau, J. Chem. Phys. 1980, 73, 5807-5816. DOI:10.1063/1.440065

24. G. M. Torrie, J.P. Valleau, J. Phys. Chem. 1982, 86, 3251-3257. DOI:10.1021/j100213a035

25. C. Lian, K. Liu, K. L. Van Aken, Y. Gogotsi, D. J. Wesolowski, H. L. Liu, D. E. Jiang, J. Z. Wu, ACS Energy Lett. 2016, 1, 2126. DOI:10.1021/acsenergylett.6b00010

26. J.W. Lee, R. H. Nilson, J. A. Templeton, S. K. Griffiths, A. Kung, B. M. Wong, J. Chem. Theory Comput. 2012, 8, 2012-2022. DOI:10.1021/ct3001156

27. A. A. Kornyshev, J. Phys. Chem. B 2007, 111, 5545-5557. DOI:10.1021/jp067857o

28. S. Mohajernia, A. Mazare, E. Gongadze, V. Kralj-Iglič, A. Ig- lič, P. Schmuki, Electrochim. Acta 2017, 245, 25-31.

DOI:10.1016/j.electacta.2017.05.115

29. J. Mähler, I. Persson, Inorg. Chem. 2012, 51, 425-438. DOI:10.1021/ic2018693

30. A.V. Dubtsov, S.V. Pasechnik, D.V. Shmeliova, A.Sh. Saidgaziev, E. Gongadze, A. Iglič, S. Kralj, Soft Matter 2018, 14(47), 9619-9630. DOI:10.1039/C8SM01529E

31. C. Outhwaite, Mol. Phys. 1976, 31, 1345-1357. DOI:10.1080/00268977600101061

32. A. Abrashkin, D. Andelman, H. Orland, Phys. Rev. Lett. 2007, 99, 077801. DOI:10.1103/PhysRevLett.99.077801

33. M. Bazant, M. Kilic, B. Storey, A. Ajdari, Adv. Coll. Int. Sci. 2009, 152, 48-88. DOI:10.1016/j.cis.2009.10.001

34. E. Gongadze, A. Iglič, Bioelectrochemistry 2012, 87, 199-203. DOI:10.1016/j.bioelechem.2011.12.001

35. E. Gongadze, A. Velikonja, S. Perutkova, P. Kramar, A. Maček-Lebar, V. Kralj-Iglič, A. Iglič, Electrochim. Acta 2014 126, 42-60. DOI:10.1016/j.electacta.2013.07.147

36. M. A. Quiroga, K. H. Xue, T. K. Nguyen, M. Tulodziecki, H. Huang, A. A. Francoa, J. Electrochem. Soc. 2014, 161, E3302E3310. DOI:10.1149/2.029408jes

37. C. Outhwaite, Mol. Phys. 1983, 48, 599-614. DOI:10.1080/00268978300100431

38. E. Gongadze, T. Slivnik, V. Kralj-Iglič, A. Iglič, Electrochim. Acta 2013, 109, 656-662.

DOI:10.1016/j.electacta.2013.07.126

39. T. Nagy, D. Henderson, D. Boda, J. Phys. Chem. B 2011, 115, 11409-11419. DOI:10.1021/jp2063244

40. A. Iglič, E. Gongadze, K. Bohinc, Bioelectrochemistry 2010, 79, 223-227. DOI:10.1016/j.bioelechem.2010.05.003

41. E. Gongadze, U. van Rienen, V. Kralj-Iglič, A. Iglič, Gen. Physiol. Biophys. 2011, 30, 130-137.

DOI:10.4149/gpb_2011_02_130

42. R. Misra, S. Das, S. Mitra, J. Chem. Phys. 2013, 138, 114703. DOI:10.1063/1.4794784

43. J. Sin, S. J. Im, K.I. Kim, Electrochim. Acta 2015, 153, 531-539. DOI:10.1016/j.electacta.2014.11.119

44. R. Schlögl, Z. Physik. Chem. 1954, 202, 379-389.

45. H. Fröhlich, Theory of Dielectrics, Clarendon Press, Oxford, UK, 1964.

46. E. Gongadze, A. Iglič, Electrochim. Acta 2015, 178, 541-545. DOI:10.1016/j.electacta.2015.07.179

47. Y. Zhang, J. Huang, J. Phys. Chem. C, 2018, 122, 28652-28664. DOI:10.1021/acs.jpcc.8b08298

48. M. Drab, E. Gongadze, L. Mesarec, S. Kralj, V. Kralj-Iglič, A. Iglič, Eletrotehniški Vestnik (Journal of Electrical Engineering and Computer Science) 2017, 84, 221-234.

49. K. Giese, U. Kaatze, R. Pottel, J. Phys. Chem. 1970, 74, 37183725. DOI: $10.1021 / \mathrm{j} 100715 \mathrm{a} 005$

50. A. Velikonja, E. Gongadze, V. Kralj-Iglič, A. Iglič, Int. J. Electrochem. 2014, 9, 5885-5894.

51. A. Velikonja, V. Kralj-Iglič, A. Iglič, Int. J. Electrochem. 2015, $10,1-7$.

52. M. Lorenzetti, E. Gongadze, M. Kulkarni, I. Junkar, A. Iglič, Nanoscale Res. Lett. 2016, 11, 378.

DOI:10.1186/s11671-016-1594-3 
53. C. Outhwaite, L. Bhuiyan, J. Chem. Phys. 1986, 84, 3461-3471. DOI:10.1063/1.450231

54. J. Yu, G. Aguilar-Pineda, A. Antillon, S. Dong, M. Lozada-Cassou, J. Coll. Int. Sci. 2006, 295, 124-134.

DOI:10.1016/j.jcis.2005.08.016

55. J. J. Lopez-Garcia, J. Hornoa, C. Grosse, J. Coll. Int. Sci. 2017, 496, 531-539. DOI:10.1016/j.jcis.2017.02.043

56. J. C. Maxwell, A Treatise on Electricity and Magnetism, vol. 1, Clarendon, Oxford, 1892.

57. I. Szalai, S. Nagy, S. Dietrich, J. Chem. Phys. 2009, 131, 154905. DOI: $10.1063 / 1.3248242$

58. I. Szalai, S. Dietrich, J. Phys.: Condens. Matter 2008, 20, 204122. DOI:10.1088/0953-8984/20/20/204122

59. A. Marcovitz, A. Naftaly, Y. Levy, J. Chem. Phys. 2015, 142, 085102. DOI:10.1063/1.4913370

60. V. Lockett, R. Sedev, J. Ralston, M. Horne, T. Rodopoulos, J. Phys. Chem. C 2008, 1124, 7486-7495.

DOI:10.1021/jp7100732
61. V. Lockett, M. Horne, R. Sedev, T. Rodopoulosb, J. Ralstona, Phys. Chem. Chem. Phys. 2010, 12, 12499-12512.

DOI:10.1039/c0cp00170h

62. M. V. Fedorov, N. Georgi, A. A. Kornyshev, Electrochem. Commun. 2010, 12, 296-299. DOI:10.1016/j.elecom.2009.12.019

63. M. V. Fedorov, A.A. Kornyshev, Electrochim. Acta 2008, 53, 6835-6840. DOI:10.1016/j.electacta.2008.02.065

64. D. F. Evans, H. Wennerström, The Colloidal Domain: where physics, chemistry, biology, and technology meet, 2nd ed., Wiley-VCH, New York, 1999.

65. D. Grahame, J. Am. Chem. Soc. 1954, 76, 4819-4823. DOI:10.1021/ja01648a014

66. A. Iglič, D. Drobne, V. Kralj-Iglič, Nanostructures in Biological Systems: Theory and Applications. Pan Stanford, New York; Boca Raton: CRC Press, 2015. DOI:10.1201/b18607

67. S. A. Safran. Statistical Thermodynamics of Surfaces, Interfaces, and Membranes, Addison-Wesley, Reading, Menlo Park, New York, 1994.

\section{Povzetek}

V članku opišemo model električne dvojne plasti, ki v okviru približka povprečnega polja upošteva asimetrično končno velikost anionov in kationov ter orientacijsko urejanje vodnih molekul v Sternovi in difuzni plasti elektrolitske raztopine v stiku z ravno naelektreno površino. Pri tem podamo tudi kratek opis nekaterih osnovnih konceptov ter pregled literature na področju teorije električne dvojne plasti. Kot primer uporabe opisanega teoretičnega modela električne dvojne plasti prikažemo vpliv velikosti anionov in kationov, debeline Sternove plasti ter orientacijskega urejanja vodnih molekul na asimetrično bimodalno diferencialno kapacitivnost električne dvojne plasti.

Except when otherwise noted, articles in this journal are published under the terms and conditions of the Creative Commons Attribution 4.0 International License 